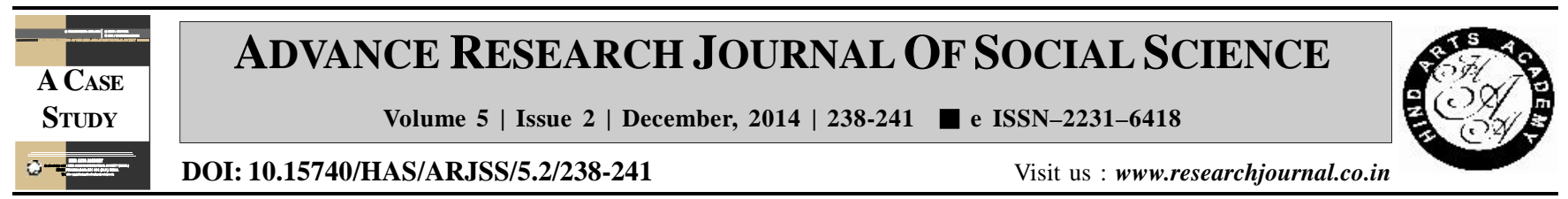

\title{
Marital satisfaction during middle adulthood
}

A. Neemi Devi* and Minoti Phukan

Department of Human Development and Family Studies, College of Home Science, Assam Agricultural University, JORHAT (ASSAM) INDIA

(Email: ah.neemi@gmail.com)

\section{ARTICLE INFO :}

Received

: 19.09 .2014

Accepted

: 23.11 .2014

KEY WORDS :

Middle age, Marital satisfaction

HOW TO CITE THIS ARTICLE :

Devi, A. Neemi and Phukan, Minoti (2014). Marital satisfaction during middle adulthood. $A d v$. Res. J. Soc. Sci., 5 (2) : 238-241.

*Author for correspondence

\begin{abstract}
The present case study was conducted to study the marital satisfaction among middle aged (20 men and 20 women). In-depth interview was conducted using semi structure questionnaire on marital satisfaction. It was revealed that both men and women were satisfied with the affection, intimate conversation, recreational companionship, honesty and openness and family commitment with their spouse. With regard to financial support maximum of the men were moderately satisfied while majority of the women were also moderately satisfied with domestic support from their spouse. Maximum of the male and female respondents were in low level of satisfaction with respect to health of their spouse. Majority of the female and male respondents were in moderate level with regard to relationship with in-laws.
\end{abstract}

